\title{
Reappraising the theme of breeding systems in Echinococcus: is outcrossing a rare phenomenon?
}

\author{
K. L. HAAG ${ }^{1,2,3 *}$, P. B. MARIN ${ }^{2}$, D. A. S. GRAICHEN ${ }^{1}$ and M. L. DE LA RUE \\ ${ }^{1}$ Programa de Pós Graduação em Genética e Biologia Molecular, Universidade Federal do Rio Grande do Sul. Caixa Postal \\ 15053, CEP 91501-970, Porto Alegre, Brazil \\ ${ }^{2}$ Departamento de Genética, Universidade Federal do Rio Grande do Sul. Caixa Postal 15053, CEP 91501-970, \\ Porto Alegre, Brazil \\ ${ }^{3}$ University of Basel, Zoological Institute, Vesalgasse 1, 4051 Basel, Switzerland \\ ${ }^{4}$ Departamento de Microbiologia e Parasitologia/CCS, Universidade Federal de Santa Maria. Av. Roraima, 1000, \\ CEP 97105-900, Santa Maria, Brazil
}

(Received 4 Fune 2010; revised 8 Fune 2010; accepted 17 August 2010; first published online 30 September 2010)

SUMMARY

Selfing has been considered the most common mode of reproduction in Echinococcus flatworms. However, population genetic studies on the asexual larval stage involving nuclear co-dominant markers have not always revealed significant heterozygote deficiencies - the expected outcome of a regularly and highly inbred population. In this study, we analysed the genetic structure of Echinococcus granulosus sensu lato populations from Southern Brazil during their adult (sexual) stage using 1 mitochondrial and 1 nuclear marker ( $\operatorname{cox} 1$ and $m d h$, respectively). We show that parasite genetic differentiation is largest among definitive hosts (domestic dogs) from different farms, suggesting that transmission is mostly maintained within a farm. Moreover, we show that heterozygote deficiencies are not significant, and we suggest that outbreeding is the most common mode of reproduction of the parasite in that region.

Key words: selfing, outcrossing, Echinococcus granulosus, flatworm, mating system.

\section{INTRODUCTION}

Echinococcus is a hermaphroditic cestode that lives in the intestine of carnivores (generally canids) during the adult phase of its life cycle. The larvae usually develop in the liver and lungs of herbivorous mammals such as rodents, artiodactyls and perissodactyls. The natural cycle is maintained through predator-prey interactions, and the domestic cycle is completed when dogs eat the uncooked viscera of infected intermediate hosts (sheep, cattle, goats etc). Echinococcosis is a globally prevalent zoonosis with considerable economical impacts. The genus Echinococcus is undergoing a taxonomic revision (Thompson and McManus, 2002) as its most common and widely distributed species, E. granulosus, contains a high degree of genetic variation correlating to its intermediate host species. Thus, some genotypes or strains of E. granulosus that had adapted to different intermediate hosts were recently split in separate species (Thompson and McManus, 2002; Nakao et al. 2007).

It has been generally accepted that selfing causes strain variation within the genus Echinococcus (Smyth and Smyth, 1964). An opposing but less-accepted explanation for strain divergence is natural selection

* Corresponding author: University of Basel, Zoological Institute, Vesalgasse 1, 4051 Basel, Switzerland. Tel: +41(0) 6126703 61. Fax: +41(0) 6126703 62. E-mail: karen.haag@unibas.ch (revised by Thompson and Lymbery, 1988). Rausch (1986) proposed that gene flow and cross-fertilization are extensive in E. granulosus, and he attributed strain differentiation to the association with distinct domestic host species. Evidence for the traditional view is the highly significant deficiency of heterozygotes and linkage disequilibrium in E. granulosus populations from Australia and Brazil (Lymbery et al. 1997; Haag et al. 1999). Nevertheless, some degree of outcrossing must occur to account for the presence of heterozygotes (Badaraco et al. 2008).

Outcrossing is believed to be more advantageous than selfing because it produces more variable offspring that might better respond to various selection pressures and suffer less from the expression of deleterious mutations (Wright, 1977; Maynard Smith, 1978). In Schistocephalus solidus, a hermaphroditic tapeworm whose cycle is maintained through fish-eating birds (definitive hosts), copepods (first intermediate hosts) and sticklebacks (second intermediate hosts), outbred parasites showed higher infectivity and developmental rates (Christen et al. 2002). Model simulations used to estimate extinction probabilities have suggested that hermaphroditism associated with selfing in the freeliving nematode Caenorhabditis elegans must have arisen relatively recently, or that low levels of outcrossing and other factors are key to the species' persistence into the present day (Loewe and Cutter, 2008). 
Most models on mating system evolution predict that a mixture of selfed and outcrossed progeny should not exist. Uyenoyama (1986) found that mixed-mating systems (with both outcrossing and selfing) would be evolutionary stable only when selffertilization and bi-parental inbreeding occur simultaneously. Indeed, it was shown that adults of $S$. solidus self-fertilize a fraction of their eggs, but the amount of selfed progeny is highly variable among individuals (Lüscher and Milinski, 2003). A mixed-mating system seems to be maintained by stochastic density fluctuations in the host (uncertainty in finding a mate increases the benefit of selfing). In Echinococcus, microscopy studies of adult worms show contradictory results, indicating either that self-insemination is the normal process of sperm transfer in E. granulosus (Smyth and Smyth, 1969), or that mating between worms is the main form of reproduction (Wang, 1998).

Understanding the mode of reproduction in the Echinococcus would enable us to predict how parasite populations respond to drugs or vaccines. Resistance mutations may spread rapidly in an outcrossing population. However, genetic studies within the group have focused mainly on uni-parental mitochondrial markers and on the larval (asexual) stage. To our knowledge, this is the first study that assesses the genetic structure of adult E. granulosus populations using both mitochondrial (uni-parental) and nuclear (bi-parental) markers.

\section{MATERIALS AND METHODS}

\section{Sampling and preparation of parasite materials}

Echinococcus adults measuring between 2 and $3 \mathrm{~mm}$ were obtained from 6 dogs on 3 farms in the rural area of Santana do Livramento, Southern Brazil. Dogs were purged with $3 \mathrm{mg} / \mathrm{kg}$ arecoline (Schantz, 1973). Worms were collected from the feces, washed in 1X PBS ( $\mathrm{pH} 7 \cdot 4$ ), and stored at $4{ }^{\circ} \mathrm{C}$ in $70 \%$ ethanol. To account for the possibility that the eggs within a gravid proglottid originated from cross-fertilization between 2 genetically distinct worms, the last proglottid was separated from the rest of the body with a scalpel. Each body part was first dried for $30 \mathrm{~min}$ at $37^{\circ} \mathrm{C}$ and then incubated in $50 \mu \mathrm{l}$ of a $3 \mathrm{ng} /$ $\mu \mathrm{l}$ proteinase $\mathrm{K}$ solution at $58^{\circ} \mathrm{C}$ for $2 \mathrm{~h}$. Proteinase $\mathrm{K}$ was inactivated at $95^{\circ} \mathrm{C}$ for $20 \mathrm{~min}$, and the eluates were stored at $-20{ }^{\circ} \mathrm{C}$ until use.

\section{PCR, SSCP and sequencing}

Three targets were amplified by PCR and subsequently analysed: (1) a $366 \mathrm{bp}$ fragment of the mitochondrial cytochrome oxydase gene (cox 1 , Bowles et al. 1992); (2) a $106 \mathrm{bp}$ region including the first intron of the cytosolic malate dehydrogenase gene ( $m d h$, referred to as $E g A g 4$ in Haag et al. 1999); and (3) a $214 \mathrm{bp}$ fragment containing the second intron of the same nuclear gene (Badaraco et al. 2008). PCR reactions were performed as previously described using $2 \mu \mathrm{l}$ of the thawed eluates as templates.

To screen for nucleotide polymorphisms of the nuclear $m d h$ gene, we used Single Strand Conformation Polymorphism (SSCP) to identify intron I and II alleles and to search for heterozygous genotypes. SSCP was performed using the GeneGel Clean SSCP kit on a GenePhor Electrophoresis Unit (GE Healthcare) following the manufacturer's instructions. The gels ran for $1 \mathrm{~h}$ at $14^{\circ} \mathrm{C}$ and $500 \mathrm{~V}$ (intron I), or $2 \mathrm{~h}$ at $12^{\circ} \mathrm{C}$ and $200 \mathrm{~V}$ (intron II). After electrophoresis, gels were silver stained using a conventional protocol.

We confirmed allele and genotype assignments for $m d h$ introns I and II by sequencing the PCR fragments that showed distinctive SSCP patterns. All cox 1 PCR products were analysed by nucleotide sequencing. Briefly, amplicons were purified using ExoSAP-IT (USB) and sequenced automatically in both directions (Macrogen). Chromatograms were inspected for quality and used to search for nucleotide polymorphisms with the CodonCode Aligner software.

\section{Statistical analyses}

We hierarchically grouped parasite genotypes into infra-populations (worms collected from a single dog) and populations (worms from all dogs on a single farm). Genetic variance was analysed by AMOVA (Excoffier et al. 1992) using the Arlequin 3.5 software (Excoffier and Lischer, 2010), and was classified into the following categories: within dogs (infra-populations), among dogs within farms (populations) and among farms (meta-population). To estimate inbreeding, we performed a second molecular variance analysis for each individual worm.

\section{RESULTS}

From a total of 49 worms, 36 showed successful amplification for the 3 markers (see Supplementary table in online version). Results for each body segment were always identical, with no exception, allowing us to pool the data from a single individual. Malate dehydrogenase introns I and II also showed consistent results (Table 1). Four mitochondrial haplotypes were present in our sample: G1 and G1b (sheep strain), G3 (buffalo strain) and G5 (cattle strain). According to the taxonomic classification proposed by Nakao et al. (2007), G1, G1b and G3 correspond to E. granulosus sensu stricto, and G5 to $E$. ortleppi. For convenience, we use here the suffix sensu lato to refer to all mitochondrial haplotypes found in our study. As Table 1 shows, every dog was 
Table 1. Genotypes of the 36 Echinococcus granulosus sensu lato adults analysed in our study

\begin{tabular}{|c|c|c|c|c|c|c|}
\hline \multirow[b]{2}{*}{ Farm } & \multirow[b]{2}{*}{ Coordinates } & \multirow[b]{2}{*}{ Dog } & \multirow[b]{2}{*}{$n$} & \multicolumn{3}{|c|}{ Genotype } \\
\hline & & & & $\cos 1$ & $m d h$ intron I & $m d h$ intron II \\
\hline P01 & 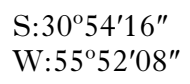 & D03 & 2 & G1b & $\mathrm{A} 1 / \mathrm{A} 1$ & Md1/Md1 \\
\hline $\mathrm{P} 12$ & $\begin{array}{l}\text { S: } 30^{\circ} 51^{\prime} 51^{\prime \prime} \\
\text { W: } 55^{\circ} 38^{\prime} 56^{\prime \prime}\end{array}$ & $\begin{array}{l}\text { D34 } \\
\text { D35 }\end{array}$ & $\begin{array}{l}1 \\
6\end{array}$ & $\begin{array}{l}\text { G3 } \\
\text { G5 }\end{array}$ & $\begin{array}{l}\text { A1/A2 } \\
\text { A3/A3 }\end{array}$ & $\begin{array}{l}\text { Md1/Md2 } \\
\text { Md3/Md3 }\end{array}$ \\
\hline $\mathrm{P} 20$ & $\begin{array}{l}\text { S: } 30^{\circ} 51^{\prime} 34^{\prime \prime} \\
\text { W: } 55^{\circ} 48^{\prime} 43^{\prime \prime}\end{array}$ & $\begin{array}{l}\text { D59 } \\
\text { D61 }\end{array}$ & $\begin{array}{l}2 \\
2 \\
1 \\
6 \\
6 \\
5 \\
1 \\
2 \\
2\end{array}$ & $\begin{array}{l}\text { G1 } \\
\text { G1 } \\
\text { G1 } \\
\text { G1 } \\
\text { G1 } \\
\text { G1 } \\
\text { G1 } \\
\text { G1 } \\
\text { G1 }\end{array}$ & $\begin{array}{l}\text { A1/A1 } \\
\text { A1/A2 } \\
\text { A2/A2 } \\
\text { A1/A1 } \\
\text { A1/A2 } \\
\text { A2/A2 } \\
\text { A1/A1 } \\
\text { A1/A2 } \\
\text { A2/A2 }\end{array}$ & $\begin{array}{l}\text { Md1/Md1 } \\
\text { Md1/Md2 } \\
\text { Md2/Md2 } \\
\text { Md1/Md1 } \\
\text { Md1/Md2 } \\
\text { Md2/Md2 } \\
\text { Md1/Md1 } \\
\text { Md1/Md2 } \\
\text { Md2/Md2 }\end{array}$ \\
\hline Total & & & 36 & & & \\
\hline
\end{tabular}

Table 2. Analysis of molecular variance (AMOVA) without the individual level

\begin{tabular}{llll}
\hline \hline $\begin{array}{l}\text { Source of } \\
\text { variation }\end{array}$ & $\begin{array}{l}\text { Sum of } \\
\text { squares }\end{array}$ & $\begin{array}{l}\text { Variance } \\
\text { components }\end{array}$ & $\begin{array}{l}\% \\
\text { Variation }\end{array}$ \\
\hline Among farms & $27 \cdot 11$ & $0 \cdot 85$ & $61 \cdot 87$ \\
Among dogs & $4 \cdot 71$ & $0 \cdot 10$ & $7 \cdot 78$ \\
$\quad \begin{array}{l}\text { on farms } \\
\text { Within dogs }\end{array}$ & $27 \cdot 54$ & $0 \cdot 42$ & $30 \cdot 35$ \\
Total & $59 \cdot 36$ & $1 \cdot 37$ & \\
\hline \hline
\end{tabular}

parasitized by a single mitochondrial haplotype with 1 exception: $\operatorname{dog}$ P20D59 contained 22 worms with haplotype G1 and 1 with haplotype G1b (Supplementary table). However, because the eluate derived from this individual did not amplify the nuclear markers, it was excluded from further analyses.

There was a slight but not significant, deficiency in $m d h$ heterozygotes in farm P20 $(n=27)$. Other populations have rather low sample sizes for testing Hardy-Weinberg proportions. One infra-population (dog P12D35, $n=6$ ) was monomorphic (Table 1). The inbreeding coefficient $(F)$ could be estimated by the deviation from $H-W$ proportions as $F=1-H / H e$ (Nei, 1987), where $H$ is the actual population heterozygosity and $\mathrm{He}$ is the expected heterozygosity under equilibrium. In farm $\mathrm{P} 20, F$ equals $0 \cdot 26$. So if $F$ is interpreted as the proportion of selfed individuals (McCauley et al. 1985), that means the parasite on that farm outcrosses $74 \%$ of the time.

When genetic variance is partitioned using AMOVA (Table 2), more than half of the total variation $(61 \cdot 87 \%)$ is found among farms (i.e. within the entire meta-population). However, an expressive fraction of the total genetic variation $(30 \cdot 35 \%)$ occurs among worms from the same definitive host (within infra-populations). Conducting the molecular variance analyses on the individual level shows
Table 3. Analysis of molecular variance (AMOVA) considering the individual level

\begin{tabular}{lrlr}
\hline \hline $\begin{array}{l}\text { Source of } \\
\text { variation }\end{array}$ & $\begin{array}{l}\text { Sum of } \\
\text { squares }\end{array}$ & $\begin{array}{l}\text { Variance } \\
\text { components }\end{array}$ & $\begin{array}{l}\% \\
\text { Variation }\end{array}$ \\
\hline Among farms & $27 \cdot 11$ & $0 \cdot 85$ & $61 \cdot 89$ \\
Among dogs on & $4 \cdot 71$ & $0 \cdot 10$ & $6 \cdot 88$ \\
$\quad$ farms & & & \\
Within dogs & $16 \cdot 54$ & $0 \cdot 12$ & $8 \cdot 96$ \\
Within & $11 \cdot 00$ & $0 \cdot 30$ & $22 \cdot 26$ \\
$\quad \begin{array}{l}\text { individual } \\
\text { worms }\end{array}$ & & & \\
$\quad$ Total & $59 \cdot 36$ & $1 \cdot 37$ & \\
\hline \hline
\end{tabular}

that the largest fraction of the infra-population variability occurs within individual worms $(22.26 \%$, see Table 3$)$. The estimated fixation indexes are as follows: $\mathrm{F}_{\mathrm{IS}}=0.29(P=0 \cdot 02) ; \mathrm{F}_{\mathrm{SC}}=0 \cdot 18(P=0 \cdot 03)$; $\mathrm{F}_{\mathrm{CT}}=0.62(P=0.00) ; \mathrm{F}_{\mathrm{IT}}=0.77(P=0.00)$.

\section{ISCUSSION}

\section{Transmission and implications for echinococcosis control}

Four Echinococcus granulosus sensu lato haplotypes (G1, G1b, G3 and G5) are circulating among the 6 farms included in our study. However, these genetic variants are not randomly distributed among dogs and, with a single exception, no dog ever harboured more than 1 parasite haplotype. Transmission seems to occur mainly within farms. The $3 \mathrm{dogs}$ from farm P20 played host to only G1 and G1b adults, while dogs from farm P12 hosted haplotypes G3 and G5. AMOVA shows that the largest fraction of genetic variance occurs among farms (61-87\%). The genetic differentiation (fixation index) of infra-populations (dogs) from different farms $\left(\mathrm{F}_{\mathrm{CT}}=0.62\right)$ is much larger than within farms $\left(\mathrm{F}_{\mathrm{SC}}=0 \cdot 18\right)$, pointing to a scenario where the parasite is transmitted primarily 
by the habit of feeding dogs uncooked viscera. Dogs in our study area do not move far from the main farmhouse (de la Rue, personal observation). Furthermore, although taeniid eggs might be passively dispersed over distances up to $10 \mathrm{~km}$ (possibly by the wind or insects), their viability is rather low (Lawson and Gemmel, 1983).

These findings suggest that educational or other control programmes performed on a farm-by-farm basis would have a good chance of successfully reducing parasite transmission. They also explain the success of a similar control programme against echinococcosis in Tasmania in 1965, which led to the eradication of the parasite (see Jenkins (2005) for a review). With no wild definitive hosts transmitting the parasite across farms, denying domestic dogs access to offal and dosing them with anti-helmintics, together with public education and vigilance at abattoirs and farm quarantine policies, would interrupt the transmission cycle. A similar programme conducted in Uruguay in 1991, in which all domestic dogs were treated with praziquantel monthly, resulted in a remarkable decrease in the prevalence of ovine echinococcosis (Oku et al. 2004). Farias et al. (2004) also conducted a dog-treatment programme in the region in Brazil where the present samples were obtained. This programme also successfully decreased the prevalence in dogs; however, because it was difficult to introduce behavioural changes in the rural population and stop the feeding of uncooked sheep viscera to dogs, the infection rate increased quickly soon after the programme finished.

\section{Selfing versus outcrossing}

Previous studies from our group on a large set of markers using the larval stage of E. granulosus sensu lato (Haag et al. 1999) suggest that the Smyth and Smyth (1964) and Rausch (1986) models of strain evolution in Echinococcus are not mutually exclusive. We proposed that both selfing and outcrossing might occur in E. granulosus populations. No study since then has taken up the question, leaving reproduction modes in Echinococcus populations still a matter of some speculation, despite their clear epidemiological implications (e.g. evolution and spread of resistant phenotypes). Mitochondrial genes became the most popular markers for studying Echinococcus molecular epidemiology, but due to their uni-parental and nonrecombining properties, they are inadequate to assess questions about breeding systems. Nuclear markers have frequently been considered to be less variable, with the exception of a microsatellite (EmsB, Bart et al. 2006), which is unfortunately repeated inside the genome, and therefore useless for assessing breeding systems as well.

Moreover, population studies have focused almost exclusively on the asexual metacestode stage.
However, comparing Echinococcus population polymorphisms in both intermediate and definitive hosts is essential to understanding the dynamics of genetic variation during the parasite's life cycle. Although it does not provide direct evidence for the mode of reproduction, it can help test hypotheses. In this present work on the adult stage of Echinococcus, as well as in our former study on the larval stage (Haag et al. 1999), we found no significant heterozygote deficiencies. Lymbery et al. (1997) and Badaraco et al. (2008) on the other hand, found significant heterozygote deficiencies. In light of the results obtained in the present study, which show that transmission among domestic animals seems to be restricted to a single farm, it is possible that the heterozygote deficiencies previously described are a consequence of subdivision (Wahlund effect). Pooling genotypes from different farms with distinct allele frequencies could lead to statistically significant heterozygote deficiencies, resembling an inbreeding effect. Badaraco et al. (2008), for example, tested the Hardy-Weinberg equilibrium for the $m d h$ locus in a pooled sample of bovine isolates from southern Brazil corresponding to haplotype G1 $(n=115)$. The frequency of alleles Md1, Md2 and Md3, was 0.42, 0.56 and 0.02 , respectively, leading to an expected frequency of genotype $\mathrm{Md} 1 / \mathrm{Md} 2$ under $\mathrm{H}-\mathrm{W}$ equilibrium equal to $0 \cdot 47$. However, the bovine hosts came from different farms, which may have had different parasite allele frequencies. If, for instance, samples from 2 farms showing allele frequencies of $\mathrm{Md} 1$ equal to 0.8 and $0.04(0.42$ on average $)$ and of M2 equal to $0 \cdot 18$ and $0.94(0.56$ on average $)$ would have been pooled, the expected heterozygosity under H-W equilibrium would be 0.29 for the first farm and 0.08 for the second! Heterozygotes have consistently been found both in E. granulosus sensu lato (Lymbery et al. 1997; Haag et al. 1999; Badaraco et al. 2008) and in E. multilocularis (Knapp et al. 2007), suggesting that cross-fertilization is not uncommon.

Indeed, the difference between the observed and expected heterozygosity in farm P20 $(F=0 \cdot 26)$, and the fixation index of infra-populations averaged over all loci $\left(\mathrm{F}_{\mathrm{IS}}=0.29\right)$ suggests that outcrossing is actually the most common mode of reproduction. In the extreme case of a completely selfed population, $F$ should equal 1, although selfing rates may vary from one region to another, depending on particular ecological conditions. Cheptou and Dieckmann (2002) showed that, contrary to previous models of breeding system evolution, the outcomes of breeding system evolution are not confined to either complete selfing or full outcrossing - even under demographic equilibrium-and that intermediate selfing rates arise under a wide range of conditions depending on the nature of competitive interactions between inbred and outbred individuals. Thus, it seems more plausible that the Smyth and Smyth (1964) and Rausch (1986) models of Echinococcus strain 
evolution represent two ends of a continuum of selfing rates.

\section{ACKNOWLEDGEMENTS}

This project was supported by the National Council of Scientific Development and Technology (CNPq, Brazil, grant number 472329/2008-1).

\section{REFERENCES}

Badaraco, J. L., Ayala, F. J., Bart, J.-M., Gottstein, B. and Haag, K. L. (2008). Using mitochondrial and nuclear markers to evaluate the degree of genetic cohesion among Echinococcus populations. Experimental Parasitology 119, 453-459.

Bart, J. M., Knapp, J., Gottstein, B., El-Garch, F., Giraudoux, P., Glowatzki, M. L., Berthoud, H., Maillard, S. and Piarroux, R. (2006). EmsB, a tandem repeated multi-loci microsatellite, new tool to investigate the genetic diversity of Echinococcus multilocularis. Infection Genetics and Evolution 6, 390-400.

Bowles, J., Blair, D. and McManus, D. P. (1992). Genetic variants within the genus Echinococcus identified by mitochondrial DNA sequencing. Molecular and Biochemical Parasitology 54, 165-174.

Cheptou, P.-O. and Dieckmann, U. (2002). The evolution of self-fertilization in density-regulated populations. Proceedings of the Royal Society of London, B 269, 1177-1186.

Christen, M., Kurtz, J. and Milinski, M. (2002). Outcrossing increases infection success and competitive ability: experimental evidence from a hermaphrodite parasite. Evolution 56, 2243-2251.

Excoffier, L. and Lischer, H. E. L. (2010). Arlequin suite ver 3.5: A new series of programs to perform population genetics analyses under Linux and Windows. Molecular Ecology Resources 10, 564-567.

Excoffier, L., Smouse, P. E. and Quattro, J. M. (1992). Analysis of molecular variance inferred from metric distances among DNA haplotypes: application to human mitochondrial DNA restriction data. Genetics 131, 479-491.

Farias, L. N., Malgor, R., Cassaravilla, C., Bragança, C. and De La Rue, M. (2004).

Echinococcosis in Southern Brazil: efforts toward implementation of a control program in Santana do Livramento, Rio Grande do Sul. Revista do Instituto de Medicina Tropical de São Paulo 46, 153-156.

Haag, K. L., Araújo, A. M., Gottstein, B., Siles-Lucas, M., Thompson, R. C. A. and Zaha, A. (1999). Breeding systems in Echinococcus granulosus (Cestoda; Taeniidae): selfing or outcrossing? Parasitology 118, 63-71.

Jenkins, D. J. (2005). Hydatid control in Australia: where it began, what we have achieved and where to from here. International Fournal for Parasitology 35, 733-740.

Knapp, J., Bart, J. M., Glowatzki, M. L., Ito, A., Gerard, S., Maillard, S., Piarroux, R. and Gottstein, B. (2007). Assessment of use of microsatellite polymorphism analysis for improving spatial distribution tracking of Echinococcus multilocularis. Fournal of Clinical Microbiology 45, 2943-2950.
Lawson, R. and Gemmel, M. A. (1983). Hydatidosis and cysticercosis: The dynamics of transmission. Advances in Parasitology 22, 331-369.

Loewe, L. and Cutter, A. D. (2008). On the potential for extinction by Muller's Ratchet in Caenorhabditis elegans. BMC Evolutionary Biology 8, 125.

Lüscher, A. and Milinski, M. (2003). Simultaneous hermaphrodites reproducing in pairs self-fertilize some of their eggs: an experimental test of predictions of mixed-mating and Hermaphrodite's Dilemma theory. Fournal of Evolutionary Biology 16, 1030-1037.

Lymbery, A. J., Constantine, C. C. and Thompson, R. C. A. (1997). Self-fertilization without genomic or population structuring in a parasitic tapeworm. Evolution 51, 289-294.

Maynard Smith, J. (1978). The Evolution of Sex. Cambridge University Press, Cambridge, UK.

McCauley, D. E., Whittier, D. P. and Reilly, L. M. (1985). Inbreeding and the rate of self-fertilization in a grape fern, Botrychium dissectum. American Fournal of Botany 72, 1978-1981.

Nakao, M., McManus, D. P., Schantz, P. M., Craig, P. S. and Ito, A. (2007). A molecular phylogeny of the genus Echinococcus inferred from complete mitochondrial genomes. Parasitology 134, 713-722.

Nei, M. (1987). Molecular Evolutionary Genetics. Columbia University Press, New York, USA.

Oku, Y., Malgor, R., Benavidez, U., Carmona, C. and Kamiya, H. (2004). Control program against hydatidosis and the decreased prevalence in Uruguay. International Congress Series 1267, 98-104.

Rausch, R. L. (1986). Life-cycle patterns and distribution of Echinococcus species. In The Biology of Echinococcus and Hydatid Disease (ed. Thompson, R. C. A.), pp. 44-80. George Allen \& Unwin, London, UK.

Schantz, P. M. (1973). Guía para el empleo del bromhidrato de arecolina en el diagnóstico de la infección por Echinococcus granulosus en el perro. Boletin Chileno de Parasitología 28, 81-90.

Smyth, J. D. and Smyth, M. M. (1964). Natural and experimental hosts of Echinococcus granulosus and E. multilocularis, with comments on the genetics of speciation in the genus Echinococcus. Parasitology 54, 493-514.

Smyth, J. D. and Smyth, M. M. (1969). Self insemination of Echinococcus granulosus in vivo. Fournal of Helminthology 43, 383-388.

Thompson, R. C. A. and Lymbery, A. J. (1988). The nature, extent and significance of variation within the genus Echinococcus. Advances in Parasitology 27, 209-249.

Thompson, R. C. A. and McManus, D. P. (2002). Towards a taxonomic revision of the genus Echinococcus. Trends in Parasitology 18, 452-457.

Uyenoyama, M. K. (1986). Inbreeding and the cost of meiosis: the evolution of selfing in populations practicing biparental inbreeding. Evolution 40, 388-404.

Wang, H. (1998). A study on morphology of reproductive organs of Echinococcus granulosus by light microscopy, transmission and scanning electron. Endemic Diseases Bulletin 3, 31-33.

Wright, S. (1977). Experimental Results and Evolutionary Deductions. University of Chicago Press, Chicago, IL, USA. 